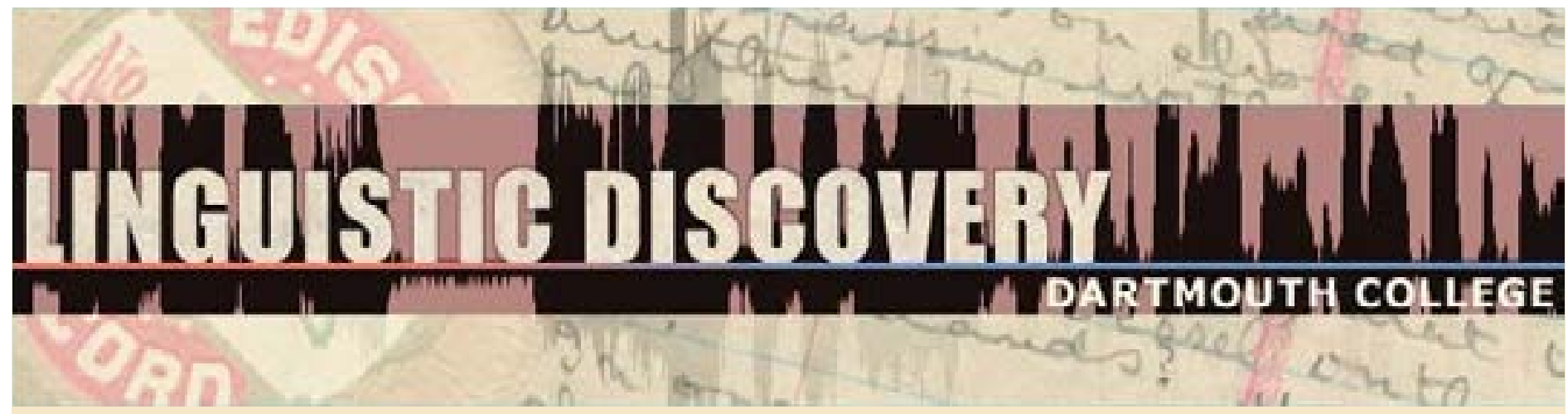

\begin{tabular}{|l|}
\hline Volume 12 \\
Issue 2 \\
2014 \\
\hline
\end{tabular}

\title{
Arguments and Adjuncts as Language- Particular Syntactic Categories and as Comparative Concepts
}

Martin Haspelmath

Max Planck Institute for Evolutionary Anthropology

doi: 10.1349/PS1.1537-0852.A.442

url: http://journals.dartmouth.edu/cgi-bin/WebObjects/ Journals.woa/1/xmlpage/1/article/442

\section{Linguistic Discovery}

Published by the Dartmouth College Library Copyright to this article is held by the authors. CC BY-NC ISSN 1537-0852 


\title{
Arguments and Adjuncts as Language-Particular Syntactic Categories and as Comparative Concepts
}

\author{
Martin Haspelmath
}

Max Planck Institute for Evolutionary Anthropology

In this short paper, I point out that there is a discrepancy between the widespread assumption that "argument" and "adjunct" should be seen as cross-linguistic categories and the practice of providing language-particular tests for the distinction. Language-particular criteria yield language-particular categories, which cannot be readily compared across languages. I discuss a possible distinguishing criterion (the pro-verb test) that might work cross-linguistically, though I also note that it may not be universally applicable. Finally I note that fortunately, the most important typological differences between languages concern the coding of participants regardless of their status as arguments or adjuncts, so that comparative concepts of argument and adjunct may not be so important for cross-linguistic comparison.

\section{The Basic Claim}

The argument-adjunct distinction is generally regarded as a very deep property of syntax, and is therefore considered to be part of general linguistics, not only of the grammars of particular languages. This general assumption is challenged in this paper, and some consequences are spelled out, mostly from the perspective of the Leipzig valency patterns project (Hartmann et al. 2013).

The basic observation is that linguists often use language-particular criteria for distinguishing arguments from adjuncts although the application of such criteria only provides evidence for language-particular categories (descriptive categories), not for universal categories.

In order to compare arguments and adjuncts cross-linguistically, one would need separate comparative concepts of arguments and of adjuncts. This does not seem to have been previously recognized. It is not fully clear, however, how one would define arguments and adjuncts from a comparative perspective, which allows only basic concepts that are equally applicable to any language. One proposal is discussed, and in the end I conclude that the distinction is perhaps not as important for cross-linguistic studies as it may have seemed.

\section{Arguments and Adjuncts as Syntactic Elements}

At least since Tesnière (1959), the distinction between two main kinds of non-predicate elements of the clause, arguments and adjuncts, has been very widely recognized by linguists, even though the terminology has become stable only relatively recently. The intuitive distinction is very clear and easy to understand: In Tesnière's famous stage metaphor, arguments are the actors which really matter to the action, and adjuncts are the props in the background. In simple textbook examples like Kim sings folk songs in the bath (Tallerman 1998: 93-94), it is very clear which elements are arguments and which are adjuncts.

However, when it comes to giving syntactic criteria for argument and adjunct status, wellknown difficulties arise, which were discussed extensively in the 1970s and later (e.g. Engel 1977, Vater 1978, Somers 1984). 
One point of view is that the argument/adjunct distinction is a semantic distinction, as seems to have been implicit in Tesnière's original discussion. Thus, Van Valin (2001: 93) says that a nominal is an argument, not an adjunct, if it is a semantic argument, i.e. an element that is conceptually necessary to saturate the predicate. And according to Farrell (2005: 31), "the basic idea is that arguments express defining elements of the process or state designated by the verb" (similarly Carnie 2002: 166). Such an approach is adopted very explicitly by Schikowski et al. (2014) in their work on Chintang valency:

"we use a strictly semantic definition of argumenthood: referential phrases instantiate arguments iff their existence and role is logically entailed by the semantics of the lexical predicate and cannot be derived from any other element in the linguistic or nonlinguistic context" (Schikowski, Paudyal and Bickel 2014)

But it has been widely recognized that there is often a discrepancy between "semantic valency" and syntactic valency, so that the two cannot be equated. In particular, it is often the case that a semantically necessary participant cannot be expressed syntactically. For example, the Russian verb molčat' 'remain silent' does not allow the syntactic expression of the addressee role, even though conceptually this role is necessary and the referent has to be inferred from the context (Apresjan 1974: 147-148). Conversely, linguists often say that passive agents, which are semantically necessary participants just as active agents, are adjuncts (e.g. Van Valin 2001: 93), so on this view passivization would be syntactic valency reduction without semantic change. Similarly, valency augmentation need not involve a semantic change; thus, German befahren 'drive (on)', which requires an Accusative object (e.g. Sie befahren die Straße 'They drive on the street'), does not have a meaning that is really different from fahren 'drive'. Dummy arguments such as it in it rains are also instances of discrepancies between semantic necessity and syntactic argumenthood.

Thus, in this paper I deal with arguments and adjuncts as syntactic elements, and I ask how they could be identified within a language and across languages. But before doing this, I will briefly discuss the question why we should make this distinction in the first place.

\section{Why Distinguish Arguments and Adjuncts?}

Syntax textbooks often present the argument-adjunct distinction as if it required no further justification, something that students need to learn about simply because many people use these terms. But they also often admit that the distinction is problematic. So do why do we need the distinction in the first place?

Interestingly, it seems that the need for such a distinction is more practical than theoretical. Levin \& Rappaport Hovav's (2005) authoritative overview of theoretical approaches to argument realization hardly mentions the distinction, and many grammatical descriptions of languages get by without it. The original impetus for a more wide-ranging discussion of the issues seems to have come from language teaching: Helbig \& Schenkel's (1969) dictionary of German verb valency derived from the needs of teaching German as a foreign language. The authors realized that their students made errors of valency and decided to address the problem systematically, by recording the valency information for every German verb. 
This reminds us of the basic rationale for distinguishing arguments from adjuncts: Arguments are verb-specific and thus have to be learned together with each verb, whereas the use of adjuncts is independent of particular verbs.

However, not all arguments are equally verb-specific. Some are quite idiosyncratic and are not predictable at all from the verb's meaning. For example, that rely requires an argument with on (rely on something) while succeed requires an argument with in (succeed in doing something) has to be learned as a set of idiosyncratic facts. But that agents are generally realized as subjects and patients as objects is far more systematic, approaching the systematicity of instrument expression by with. English is quite typical in this regard, and impressionistically even seems to have more cases of idiosyncratic valency than other languages.

So for practical purposes, it would perhaps be sufficient to list the idiosyncratically expressed arguments of those verbs that have them. And for languages that have fewer (or perhaps no) verbs with idiosyncratic valency, the relevance of the argument-adjunct distinction would not be as high.

\section{Language-Particular Criteria for the Argument-Adjunct Distinction}

Syntax textbooks and more theoretical works are full of language-particular criteria for distinguishing between arguments and adjuncts. This section lists a few more or less random examples of such criteria. It would be easy to multiply them.

Helbig \& Schenkel (1969: 32) observe that in German, adverbial adjuncts such as am Vormittag 'in the morning' may occur in post-participle position (in the postfield, after the sentence bracket), while adverbial arguments (such as dorthin 'there' in (1)) may not:

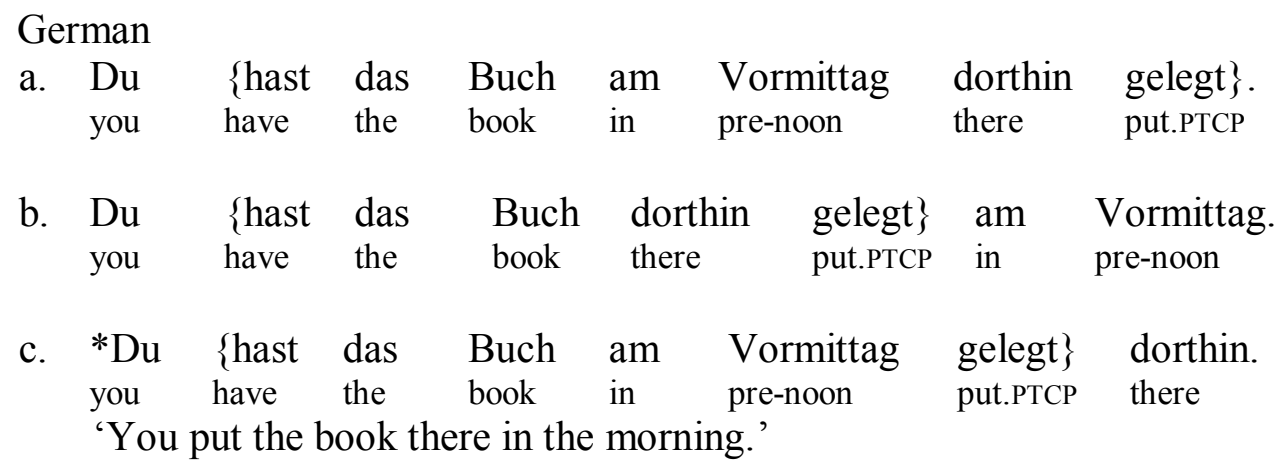

A similar language-particular word-order criterion is cited by Farell (2005: 35-36) for Tagalog: Only adjuncts such as para kay Pedro 'for Pedro' may be preposed to preverbal position:

(2) Tagalog

$\begin{array}{lllllll}\text { a. Para kay } \quad \text { Pedro ko } & \text { binili } & \text { ang } & \text { libro-ng } & \text { ito. } \\ \text { for ART Pedro 1SG.GEN } & \text { bought } & \text { NOM } & \text { book-LINKER } & \text { this } \\ \text { 'For Pedro, this book was bought by me.' } & & \end{array}$




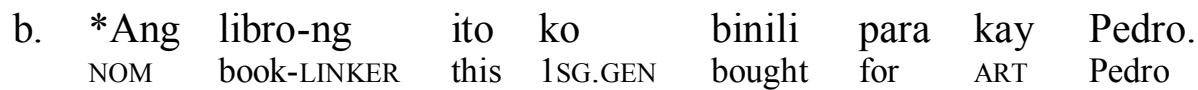
'This book was bought by me for Pedro.'

And likewise for English, Kay (2005: 92) notes that adverbial adjuncts can be readily preposed, while adverbial arguments are much more restricted:

(3) English

a. In the closet, the top was spinning.

b. *Off the table, the top was spinning.

Sometimes different relativization strategies are cited. For example, for Sliammon, a Salishan language, Watanabe (2014) observes that oblique phrases which are arguments ("oblique objects") are relativized without a special marker (cf. 4), while adjunct ("non-core") oblique phrases are relativized by means of the nominalizing proclitic $a x^{w}=$ (cf. 5). The subject of the relative clause is marked as a possessor.

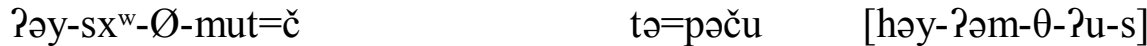

good-CAUS-3OBJ-very=1SG.INDC.SBJ DET=basket make-IND-TR.1SG.OBJ-PAST-3POSS

'I like the basket she made for me.' (Lit. I like the basket [her having made for me])

$$
\begin{aligned}
& \text { Pəy-sx }{ }^{\mathrm{w}}-\varnothing \text {-mut-as } \quad \check{\text { sə }}=\text { ?aya? } \quad\left[\mathrm{x}^{\mathrm{w}}=\theta \mathrm{u}-\mathrm{Pu}-\mathrm{s}\right] \\
& \text { good-CAUS-3OBJ-very-3ERG DET=house NOM-go-PAST-3POSS }
\end{aligned}
$$

In other cases, authors appeal to very simple coding properties of clausal elements. Thus, Margetts (2002: 614) says that arguments in Saliba (an Oceanic language of Papua New Guinea) lack postpositions, while adjuncts have postpositions. Thus, in (6) the recipient phrase 'to Maria' is an adjunct, because of the postpositional flagging.

Saliba (Margetts 2002: 629)
Leta wa ye hetamali
letter the 3SG send
'He sent the letter to Maria.'

\section{Language-Particular Criteria Define Descriptive Categories}

It needs to be kept in mind that the language-particular criteria for argument-adjunct distinctions in different languages that we saw in the last section give us language-particular categories. "Arguments" as defined by word-order criteria in German are not the same thing as "arguments" as defined by relativization in Sliammon, for example. Thus, these are not notions of general linguistics, but notions of language-particular descriptive linguistics.

This simple fact seems to be overlooked routinely by linguists. Very commonly they seem to assume that arguments and adjuncts are concepts that must be relevant for all languages, that exist universally, even though in some languages they are somewhat hidden and can be discovered only by linguists' ingenuity, using different criteria in different languages. But 
different criteria yield different categories, even if we use the same labels ("argument", "adjunct") to describe these categories. Thus, the kinds of criteria that we saw in $\S 4$ are relevant only in language-particular contexts, and not in general discussions of arguments, adjuncts or valency as features of human language.

However, there is a conceivable alternative to the above conclusion: "Argument" and "adjunct" could be cross-linguistic categories that (at least potentially) exist in all languages and whose existence is independent of language-particular criteria, probably because they are innate categories of Universal Grammar (UG). Such a view is fact fairly widespread with respect to grammatical features of various sorts, especially in generative grammar and other restrictivist approaches (cf. Haspelmath 2014 for discussion of restrictivist vs. non-apriorist approaches). But if that is the case, the tests for argumenthood and adjuncthood that we saw in $\S 4$ are not defining criteria, but are merely "diagnostics" that help us draw a distinction that is somehow established independently. As was explained clearly by Zwicky (1985) and discussed recently in Haspelmath $(2014+)$, generative linguists generally refrain from defining the categories they work with because they see these categories not as tools for language description by linguists, but as innate elements of the language system. Linguists can use whatever hints they find to detect these preestablished categories in particular languages. In particular, they can use different tests for different languages, somewhat like doctors can use different symptoms in different patients to diagnose a disease (Zwicky 1985).

But of course, the argument-adjunct distinction is not a prominent category in generative grammar. Phrase structure principles such as traditional X-bar theory make a distinction between specifiers (sisters of $\mathrm{X}^{\prime}$ and daughters of XP) and complements (sisters of X). Phrase-structure adjuncts, i.e. sisters of $X^{\prime}$ that are also daughters of $X^{\prime}$ (Carnie 2008: 122), play a much less prominent role, and there is only a rather tenuous relationship between such phrase-structural objects and what has been called "adjunct" in the non-generative literature.

Thus, I would assume that most of the authors who propose language-particular criteria for distinguishing between arguments and adjuncts as in $\$ 4$ do not have in mind any generative or otherwise innate concept. Their criteria therefore give us language-particular categories.

\section{Arguments and Adjuncts as Comparative Concepts?}

To carry out cross-linguistic research, linguists need comparative concepts (Haspelmath 2010), i.e. concepts that are applicable in the same way to all languages, using the same criteria. Thus, if we want to study valency cross-linguistically, we need to identify arguments and distinguish them from adjuncts in a way that is comparable across languages. In bringing together the authors of the Valency Patterns Leipzig (ValPaL) database (Hartmann et al. 2013), we were aware of this, and we proposed a definition of argument that we hoped would be applicable to any language. We defined "argument" in the following way:

An argument of a verb is a phrase whose occurrence is made possible by a specific verb, and which therefore cannot occur with a generic verb. This can be tested by attempting to move a phrase into a neighbouring clause with an anaphoric verb, as shown in (1a, 1c). Adjuncts, by contrast, are not tied to particular verbs and can therefore be moved out into a clause with an anaphoric verb $(1 b, 1 d)$ : 
(1)

a. I wrote a letter. $>*$ I wrote, and I did a letter.

b. I wrote with a pen. > I wrote, and I did it with a pen.

c. I put the book on the table.

*I put the book, and this happened on the table.

d. I wrote the letter on the table. $>$

I wrote the letter, and this happened on the table.

This way of identifying arguments has often been used in the literature on valency. An early application to a language other than German or English is Happ (1976). This author gives the paradigm in (7-8).

$\begin{array}{llll}\text { Trimalchio } & \text { bibit } & \text { totam } & \text { noctem. } \\ \text { Trimalchio } & \text { drinks } & \text { all.ACC } & \text { night.ACC }\end{array}$

'Trimalchio drinks all night.'

b. Trimalchio bibit et id facit totam noctem. Trimalchio drinks and this does all.ACC night.ACC

'Trimalchio drinks, and he does this all night.'

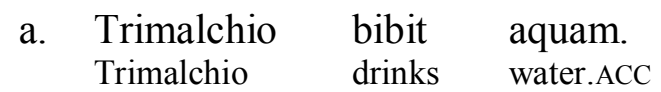

'Trimalchio drinks water.'

b. *Trimalchio bibit et id facit aquam. Trimalchio drinks and this does water.ACC

'*Trimalchio drinks, and he does this water.'

We assumed that all languages have anaphoric verbs of one kind or the other, just as all languages have anaphoric nominal expressions, so that this test should be applicable universally, and should yield a comparative concept of argument that can be applied to all languages, so that we can compare languages with respect to their valencies without assuming a pre-established, innate notion of argument, and without appealing to semantic criteria exclusively.

This test sometimes gives results that are not fully in line with what one would expect on the basis of semantic criteria. Thus, the German "free Dative" (expressing a beneficiary, similar to the preposition für) turns out to be an argument according to this criterion:

$\begin{array}{llllll}\text { a. } & \text { hat für mich einen } & \begin{array}{l}\text { Kuchen } \\ \text { he }\end{array} \text { hacken. } \\ \text { he hased }\end{array}$

'He baked a cake for me.'

b. Er hat einen Kuchen $\begin{aligned} & \text { gebacken, und } \\ & \text { he has a }\end{aligned}$
cake

das hat er für mich getan. das hat das that has he for me done that has that 'He baked a cake, and he did this for me.' 
$\begin{array}{lllll}\text { a. } & \text { hat } & \text { mir } & \text { einen } & \text { Kuchen } \\ \text { he has } & \text { me.DAT } & \text { a } & \text { cake } & \text { baked }\end{array}$

'He baked me a cake.'

b. *Er hat einen Kuchen gebacken, und das hat er mir getan. he has a cake baked and that has he me.DAT done

'*He baked a cake, and he did me this.'

From a semantic point of view, the free Dative has usually been regarded as a non-essential element, so the test does not seem to be sensitive exclusively to semantic features in German.

However, it appears that the expectation that all languages allow this criterion was too optimistic. At least one author of the forthcoming handbook of valency, Frank Seifart, notes that in Bora, it is not possible to apply this test (Seifart 2014), and even in Russian anaphoric verbs like do so or do it seem to sound unnatural (Andrej Malchukov, p.c.). We definitely need more discussion of the issue of how to define arguments cross-linguistically, so the jury is still out, but it may be that no good cross-linguistic definition of arguments and adjuncts as syntactic elements that largely coincides with our intuitions will be possible.

\section{Comparing Valency without a Comparative Concept of Argument}

Fortunately, it turns out that it is possible to compare important aspects of participant expression across languages without using a well-defined notion of argument.

Even though in Hartmann et al. (2013) we set out to compare the valency patterns across languages (in the spirit of Tsunoda (1985) and Malchukov (2005)), in reality we were interested primarily in the expression of a fairly circumscribed number of participants, namely those that have theme, patient, experiencer and stimulus roles and the like. Agents and locations are expressed very uniformly across languages, and we neither expected nor found anything particularly surprising in the ValPaL database with respect to their expression. Likewise, instruments tend to behave quite uniformly. So it is precisely those kinds of partcipants whose status as arguments is the most contentious (locations, instruments, passive agents) that are expressed in the least variable way.

In practice, we proceeded as follows: We gave the language experts that filled in our questionnaire a list of verb meanings, each with a set of possible or likely roles, described by means of English labels and role frames, as well as English example sentences, as in (11).
a. LIKE
b. WASH
E likes $M$
c. LEAVE
A washes $P$
d. TAKE
A left L
e. CARRY
A takes $P($ from $X)$
f. CUT
A carries $\mathrm{T}$ (to $\mathrm{X}$ )
A cuts $P$ (with $I$ )

The boy liked his new toy.

The mother washed the baby.

The boy left the village.

The man took the money from his friend.

The men carried the boxes to the market.

The woman cut the bread with a sharp knife.

In the "role frames" (in the second column), we parenthesized some of the possible roles, because we thought that they might be less essential, but we did not ascribe any significance to this. The contributors were supposed to decide independently whether a participant is an argument (and thus included in the verb's valency frame) or an adjunct (and thus not included). 
But the results were not particularly consistent, and we realized that in general, the authors of ValPaL did not seem to have good independent reasons for including a participant or leaving it out. In many cases, they seem to have simply followed our role frames and included all those participants in the valency frame that we included in the role frame.

However, for our goal of capturing salient differences between languages, this did not matter much, because the salient differences concern the participants with theme, patient, experiencer and stimulus roles (and the like), and these are always included in the role frames. There are two primary ways in which argument coding can be compared readily on the basis of ValPaL data.

On the one hand, we can look at the coding of individual participant roles, which we call "microroles" (Van Valin's 2001: 29 "verb-specific semantic roles"). Thus, we can ask whether the 'helpee' role and the 'hittee' role is expressed in the same way (as in English) or is expressed differently (as in Russian), and so on. In Hartmann et al. (2014), we call this approach "microrole alignment".

On the other hand, we can group the participants in our valency frames into argument types such as A and P (Haspelmath 2011), where A is defined as an argument that is coded like the 'breaker' participant of the 'break' verb, and $\mathrm{P}$ is defined as an argument that is coded like the 'broken thing' participant, when both of these are expressed simultaneously. In Haspelmath \& Hartmann (2014+), we show that some of the previous ideas about transitivity prominence are confirmed by our $\mathrm{ValPaL}$ data, while others are not confirmed. Again, these are very interesting and relevant results, but they do not depend crucially on a distinction between arguments and adjuncts at a cross-linguistic level, let alone at a language-particular level.

Thus, even though we began the valency patterns project with the assumption that valency could be identified in all languages, my current view is somewhat closer to Jacobs's (1994) deconstruction of the "valency" concept. According to Jacobs, the original valency concept really consists of seven different (though not unrelated) concepts: obligatoriness, involvement, semantic necessity, exocentricity, formal specificity, selectional restrictions, and associatedness. What we have been able to study in our comparative work is the "formal specificity" of many of the verbs" participants, even without a clear comparative concept of "argument".

And perhaps this is all we need. If we were able to identify arguments and adjuncts in a clear and unambiguous (and intuitively satisfying) way across languages, we would be able to ask further questions, e.g. whether verbs tend to have more arguments in some languages than in others. We cannot ask such questions with our current data, but maybe there is no great loss. After all, nobody has suggested "number of arguments per verb" as a typological parameter.

\section{References}

Apresjan, Jurij Derenikovič. 1974. Leksičeskaja semantika: sinonimičeskie sredstva jazyka. Moskva: Nauka.

Carnie, Andrew. 2002. Syntax: a generative introduction. Malden, MA: Blackwell.

-----. 2008. Constituent structure. Oxford: Oxford University Press.

Engel, Ulrich. 1977. Syntax der deutschen Gegenwartssprache. Berlin: E. Schmidt.

Farrell, Patrick. 2005. Grammatical relations. Oxford: Oxford University Press.

Happ, H. 1976. Grundfragen einer Dependenz-Grammatik des Lateinischen. Göttingen: Vandenhoeck \& Ruprecht.

Hartmann, Iren, Martin Haspelmath \& Bradley Taylor (eds.) 2013. Valency Patterns Leipzig. Leipzig: MPI for Evolutionary Anthropology. 
Hartmann, Iren, Martin Haspelmath \& Michael Cysouw. 2014. Identifying semantic role clusters and alignment types via microrole coexpression tendencies. Studies in Language.

Haspelmath, Martin. 2010. Comparative concepts and descriptive categories in crosslinguistic studies. Language 86/3.663-687.

----. 2011. On S, A, P, T, and R as comparative concepts for alignment typology. Lingustic Typology 15/3.535-567

-----. 2014. Comparative syntax. The Routledge Handbook of Syntax, ed. by Andrew Carnie, Yosuke Sato, and Dan Siddiqi, 490-508.

-----. 2014+. Defining vs. diagnosing linguistics categories: a case study of clitic phenomena. Categories, ed. by Joanna Błaszczak. Berlin: De Gruyter Mouton.

Haspelmath, Martin \& Iren Hartmann. 2014+. How widespread is transitive encoding? Forthcoming.

Helbig, Gerhard and Wolfgang Schenkel. 1969. Wörterbuch zur Valenz und Distribution deutscher Verben. Leipzig: Bibliographisches Institut.

Jacobs, Joachim. 1994. Kontra Valenz. Trier: Wissenschaftlicher Verlag Trier.

Kay, Paul. 2005. Argument structure constructions and the argument-adjunct distinction. Grammatical constructions: Back to the roots, ed. by Mirjam Fried and Hans Christian Boas, 71-98. Amsterdam: Benjamins.

Levin, Beth and Malka Rappaport Hovav. 2005. Argument realization. Cambridge: Cambridge University Press.

Malchukov, Andrej. 2005. Case pattern splits, verb types, and construction competition. Competition and variation in natural languages: The case for case, ed. by Mengistu Amberber and Helen de Hoop, 73-117. London: Elsevier.

Schikowski, Robert, Netra P. Paudyal, and Balthasar Bickel. 2014. Valency classes in Chintang. Valency classes: a comparative handbook, ed. by Bernard Comrie and Andrej L. Malchukov. Berlin: De Gruyter Mouton.

Seifart, Frank. 2014. Valency classes in Bora (Peru). Valency classes: a comparative handbook, ed. by Bernard Comrie and Andrej L. Malchukov. Berlin: De Gruyter Mouton.

Tallerman, Maggie. 1998. Understanding syntax. London: Arnold.

Tesnière, Lucien. 1959. Éléments de syntaxe structurale. Paris: Klincksieck.

Tsunoda, Tasaku. 1985. Remarks on transitivity. Journal of Linguistics 21.385-396.

Van Valin, Robert D. 2001. An introduction to syntax. Cambridge: Cambridge University Press.

Vater, Heinz. 1978. On the possibility of distinguishing between complements and adjuncts. Valence, semantic case and grammatical relations, vol. 1, ed. by Werner Abraham, 21-45. Amsterdam: Benjamins.

Watanabe, Honore. 2014. Valency classes in Sliammon. Valency classes: a comparative handbook, ed. by Bernard Comrie and Andrej L. Malchukov. Berlin: De Gruyter Mouton.

Zwicky, Arnold M. 1985. Clitics and particles. Language 61/2.283-305.

Author's Contact Information:

Martin Haspelmath

Max Planck Institute for Evolutionary Anthropology

Deutscher Platz 6

04103 Leipzig, Germany

haspelmath@eva.mpg.de 